\title{
ANALISIS PERBANDINGAN KINERJA SISTEM DISTRIBUSI PANAS PADA VARIASI RUANG MESIN PENGERING IKAN
}

\author{
Ahmad Aryadillah'), Aqli Mursadin') \\ 1,2Program Studi Teknik Mesin \\ Fakultas Teknik Universitas Lambung Mangkurat \\ JL. Akhmad Yani Km.36 Banjarbaru, Kalimantan Selatan,70714 \\ Telp. 0511-4772646, Fax 0511-4772646 \\ E-mail : ahmad.aryadillah2@gmail.com
}

\begin{abstract}
The purpose of this research is to know the heat distribution system in three types of fish dryers. The variations of the dryer room were fire-tube type, fire-tube type with bevel, and air-tube type. This study was conducted by simulating airflow and heat transfer that occurred in each dryer room variation by using CFD software. In the simulation, the dryer was heated using an electric heating element with a temperature of $80^{\circ} \mathrm{C}$ and the results display hot air flow moving in the drying chamber. In the fire-tube type dryer room obtained average temperature of $46.74^{\circ} \mathrm{C}$. In the fire-tube type dryer room with the bevel obtained an average temperature of $44.40^{\circ} \mathrm{C}$. While the type of air-tube shows average temperature results of $34.31^{\circ} \mathrm{C}$. From the simulation, we known that the fire-tube type has the best heat distribution system.
\end{abstract}

Keywords: Fire-tube, bevel, Air-tube, simulation

\section{PENDAHULUAN}

Sebagai negara maritim, Indonesia dikelilingi oleh lautan yang menghasilkan berbagai macam sumber daya kelautan yang melimpah salah satunya adalah ikan. Ikan merupakan sumber daya laut yang memiliki nilai gizi tinggi sehingga menjadi salah satu bahan makanan yang sangat digemari. Bahan ini diolah menjadi berbagai jenis masakan salah satunya adalah ikan asin. Ikan asin dibuat dengan cara mengeringkan ikan di bawah terik matahari sehingga kadar air dalam ikan menurun. Hal ini juga membuat ikan dapat awet dan terhindar dari jamur.

Proses pengeringan yang masih menggunakan energi matahari masih mengalami berbagai kendala, diantaranya adalah perubahan cuaca dan perubahan musim yang memperlambat proses pengeringan. Hal ini dapat membuat ikan mudah busuk sebelum kering sempurna. Selain itu, lingkungan lahan yang digunakan untuk mengeringkan ikan juga sangat berpengaruh terhadap proses pengeringan dengan menggunakan energi panas matahari.

Dari permasalahan diatas maka dirancanglah sebuah sistem distribusi panas yang mampu mempercepat proses pengeringan tanpa bergantung pada kondisi cuaca dan mampu mendistribusikan panas secara merata sehingga ikan dapat terhindar dari jamur dan menjadi kering. 


\section{Perpindahan Panas Konduksi}

Perpindahan panas konduksi adalah perpindahan energi panas melalui zat padat yang tidak ikut mengalami perpindahan. Artinya, perpindahan kalor pada suatu zat tersebut tidak disertai dengan perpindahan partikel - partikelnya. Misalnya benda yang terbuat dari logam akan terasa hangat atau panas jika ujung benda dipanaskan hal ini dikarenakan atom - atom di dalam benda padat akan bergetar ketika menerima energi panas kemudian atom - atom ini akan membuat atom - atom di sekitarnya ikut bergetar sehingga energi yang diterima oleh atom atom tersebut akan terdistribusi secara stasioner. Dalam perpindahan tersebut, atom - atom ini adalah media penghantar atau dapat disebut sebagai konduktor. Konduktor adalah benda yang dapat menghantarkan energi panas melalui partikel partikelnya dengan baik.

Cepat atau lambatnya perpindahan panas yang terjadi dalam suatu bahan diukur sebagai konduktivitas termal. Konduktivitas termal adalah suatu besaran yang menunjukkan kemampuan suatu benda untuk menghantarkan energi panas melalui partikelnya. Konduktivitas termal merupakan suatu fenomena dimana perbedaan temperatur menyebabkan transfer energi termal dari satu daerah benda panas ke daerah yang memiliki temperatur lebih rendah. Benda yang konduktivitas termalnya hampir sama atau sama dengan nol disebut isolator. Isolator tidak dapat menghantarkan energi panas dengan baik.

\section{Perpindahan Panas Konveksi}

Konveksi adalah perpindahan energi panas dari tempat yang lebih panas ke tempat yang lebih dingin, ketika cairan atau gas bergerak ke daerah yang lebih dingin ke daerah yang lebih panas. Hal ini menghasilkan sirkulasi materi yang terusmenerus sampai ada kesetaraan suhu. Misalnya ketika air dipanaskan dalam panci, maka air akan mendidih.

a. Konveksi alamiah

Konveksi alami (konveksi bebas) terjadi karena fluida bergerak secara alamiah dimana pergerakan fluida tersebut lebih disebabkan oleh perbedaan massa jenis fluida akibat adanya variasi suhu pada fluida tersebut.

b. Konveksi paksa

konveksi paksa terjadi karena bergeraknya fluida bukan karena faktor alamiah. Fluida bergerak karena adanya alat yang digunakan untuk menggerakkan fluida tersebut, seperti kipas, pompa, blower dan sebagainya.

\section{Perpindahan Panas Radiasi}

Radiasi adalah perpindahan energi kalor dikarenakan rambatan foton yang tak terorganisir. Setiap benda pada hakikatnya terus memancarkan foton - foton secara acak dalam fungsi arah dan waktu, dan tenaga netto yang ditransfer oleh foton foton yang dipancarkan tersebut adalah kalor. Besarnya energi kalor yang dapat dipancarkan suatu benda tergantung pada daya pancarnya. Besarnya daya pancar setiap benda berbeda - beda yang dapat ditunjukkan oleh persamaan Stefan Boltzmann yang berbunyi "Energi yang dipancarkan oleh suatu permukaan akan sebanding dengan pangkat empat suhu mutlak permukaan terseebut".

Pada umumnya daya emisi (pancar) sama dengan daya serap/absorbsi suatu benda sehingga dapat disimpulkan bahwa pemancar radiasi yang baik juga dapat menyerap radiasi dengan baik. Pemancar yang buruk juga merupakan penyerap yang buruk juga. 


\section{CFD (Computational Fluid Dynamics)}

Dinamika fluida komputasi, biasanya disingkat sebagai CFD (Computational Dynamics Fluid), adalah cabang dari mekanika fluida yang menggunakan metode numerik dan algoritma untuk memecahkan dan menganalisis masalah yang melibatkan studi aliran fluida. Pada analisis ini komputer digunakan untuk melakukan perhitungan yang diperlukan untuk mensimulasikan interaksi cairan dan gas dengan permukaan yang didefinisikan oleh kondisi batas, dengan kecepatan perhitungan komputer, agar hasil analisis yang lebih baik dapat dicapai. Di berbagai penelitian yang sedang berlangsung, banyak menghasilkan perangkat lunak yangmeningkatkan akurasi dan kecepatan skenario simulasi yang kompleks seperti aliran fluida secara transonik atau turbulen. Validasi awal dari perangkat lunak tersebut dilakukan menggunakan terowongan angin dan validasi akhir menggunakan tes penerbangan.

\section{METODE PENELITIAN}

Penelitian ini dilakukan dengan metode simulasi yaitu dengan mensimulasikan aliran udara panas pada tiga rancangan sistem distribusi panas ruang pengering menggunakan software SOLIDWORKS 2015. tiga jenis rancangan tersebut antara lain : tipe fire-tube, fire-tube dengan bevel, dan tipe air-tube.

Adapun diagram alir penelitian ini dapat dilihat pada Gambar 1.

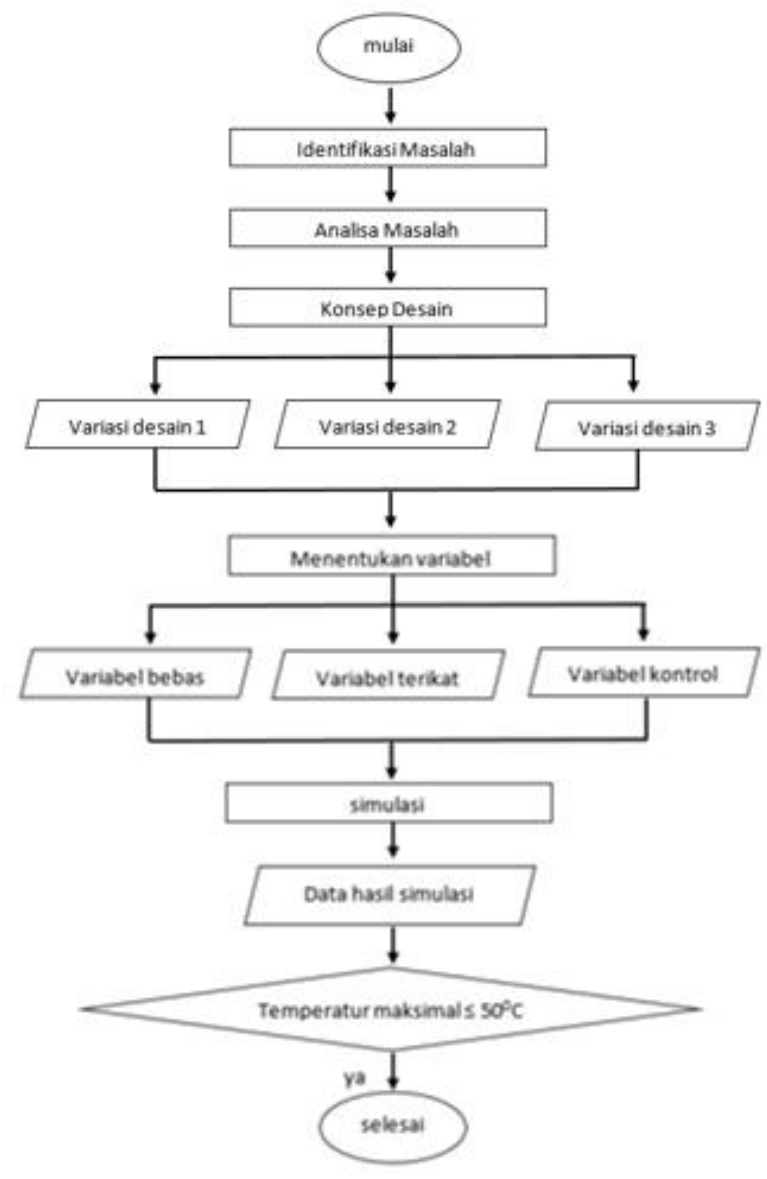

Gambar 1. Diagram Alir Penelitian 


\section{HASIL DAN PEMBAHASAN}

Setelah rancangan dibuat, kemudian dilakukan proses analisa dan simulasi distribusi panas pada rancangan alat. Simulasi dilakukan menggunakan flow simulation pada software Solidworks 2015.

\section{Desain Ruang Pengering}

Ruang pengering pada rancangan ini merupakan wadah penampungan ikan yang akan dikeringkan dengan menggunakan udara yang sebelumnya telah dipanaskan. Ruang pengering didesain berbentuk kubus dengan dimensi $1000 \mathrm{~mm} x$ $600 \mathrm{~mm}$ x $350 \mathrm{~mm}$ dengan material stainless steel 302 karena dinilai memiliki konduktivitas termal yang rendah. Dimensi rancangan ruang pengering dapat dilihat pada Gambar 2.

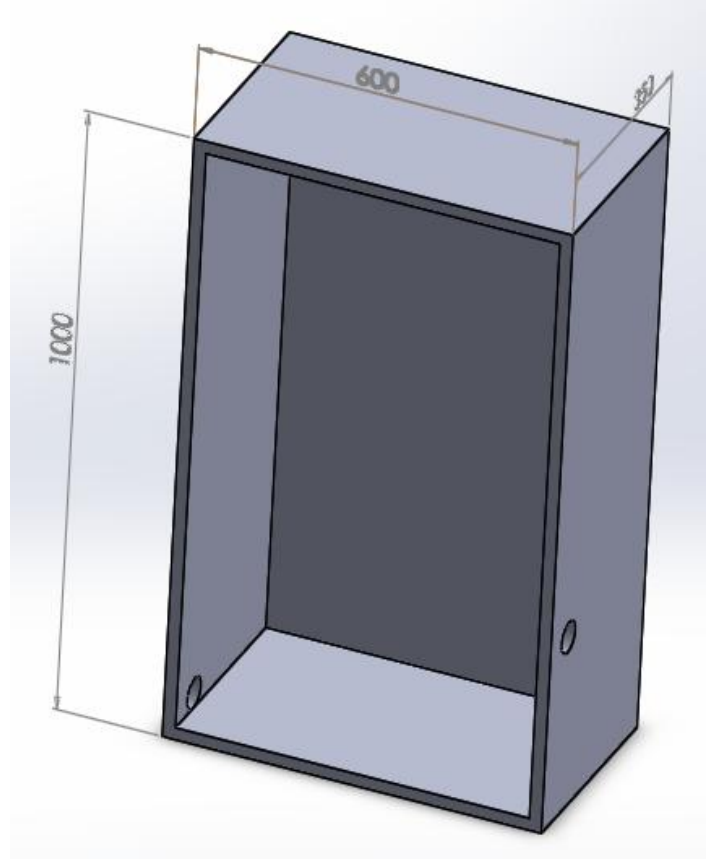

Gambar 2. Dimensi Rancangan

1. Tipe fire-tube

Desain ini menggunakan sistem distribusi panas tipe fire-tube yaitu api hasil pembakaran dialirkan melalui tube untuk memanaskan udara di dalam ruang pengering. Rancangan tipe ini dapat dilihat pada Gambar 3. 


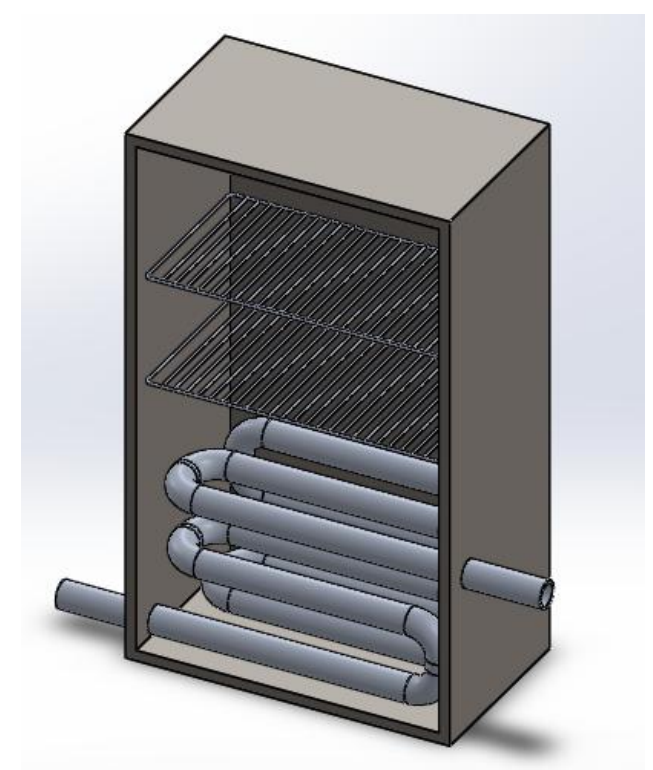

Gambar 3. Desain Ruang Pengering Tipe Fire-Tube

\section{Tipe air-tube}

Desain ini menggunakan sistem distribusi panas air-tube yaitu udara dari luar dialirkan menggunakan blower melalui tube menuju ruang pengering. Udara yang dialirkan tersebut akan dipanaskan di ruang bakar sampai menuju ruang pengering. Rancangan tipe ini dapat dilihat pada Gambar 4.

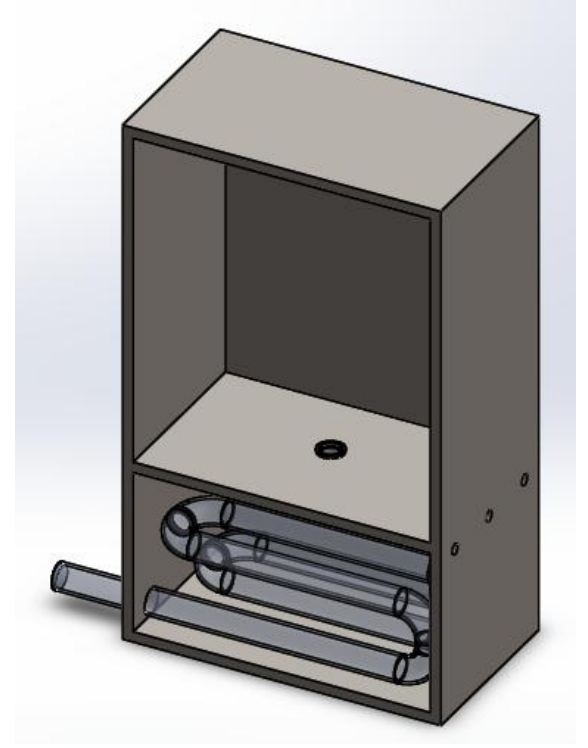

Gambar 4. Desain Ruang Pengering Tipe Air-Tube

3. Tipe fire-tube dengan bevel

Sistem ini hampir sama dengan tipe fire-tube hanya saja pada tipe ini dibuat bevel. Rancangan tipe ini dapat dilihat pada Gambar 5. 


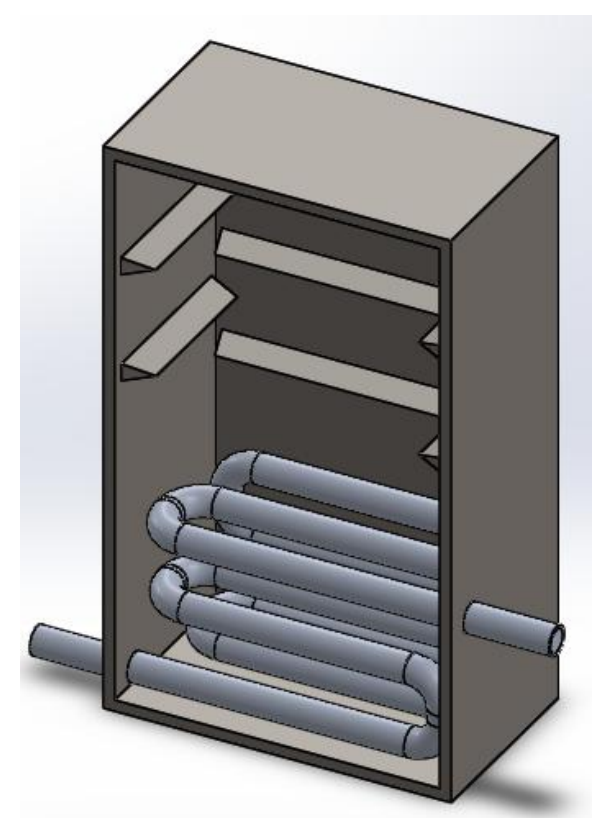

Gambar 5. Desain Ruang Pengering Tipe Fire-Tube Dengan Bevel

\section{Hasil Simulasi}

Simulasi dilakukan menggunakan fitur flow simulation pada software Solidworks dengan menempatkan 4 point parameter pada setiap rancangan. Simulasi dilakukan untuk mengatahui suhu masing - masing point parameter setelah dipanaskan selama 5 menit. Hasil dari simulasi masing - masing rancangan adalah sebagai berikut :

1. Tipe fire-tube

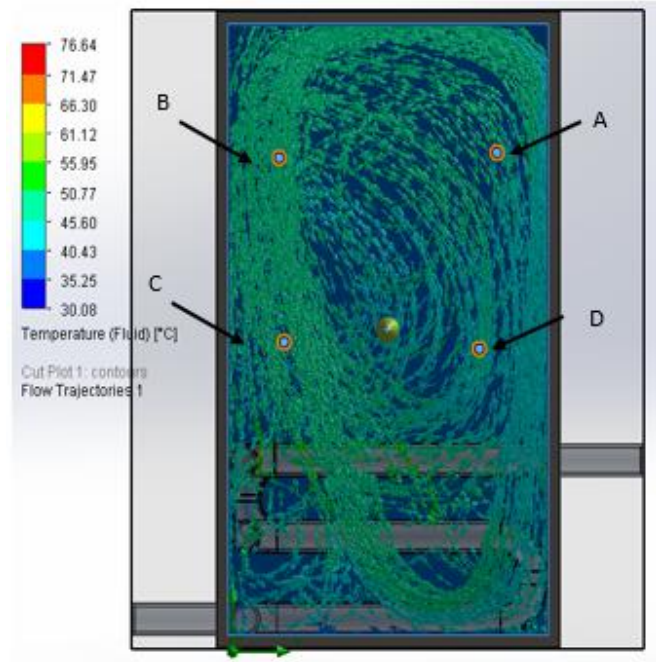

Gambar 6. Hasil Simulasi Tipe Fire-Tube

Dari hasil simulasi didapatkan data temperatur pada keempat titik yang ditunjukkan dalam Tabel 1. 
Tabel 1. Hasil simulasi tipe fire-tube

\begin{tabular}{|c|c|c|c|c|}
\hline \multicolumn{2}{|c|}{ Point Parameters } & & & \\
\hline \multicolumn{5}{|c|}{ Global Coordinate System } \\
\hline \multicolumn{3}{|c|}{ Medium - Fluid; Time $=300 \mathrm{~s}$} & & \multirow{2}{*}{$\begin{array}{l}\text { Temperature } \\
\text { (Fluid) }\left[{ }^{\circ} \mathrm{C}\right]\end{array}$} \\
\hline Point & $X[\mathrm{~m}]$ & $\mathrm{Y}[\mathrm{m}]$ & $\mathrm{Z}[\mathrm{m}]$ & \\
\hline$A$ & 0,46252 & 0,78383 & 0,82662 & 46,3456125 \\
\hline$B$ & 0,08206 & 0,77601 & 0,82662 & 47,69149817 \\
\hline $\mathrm{C}$ & 0,09034 & 0,48629 & 0,82662 & 47,12733835 \\
\hline $\mathrm{D}$ & 0,43180 & 0,47594 & 0,82662 & 45,81989871 \\
\hline
\end{tabular}

2. Tipe air-tube

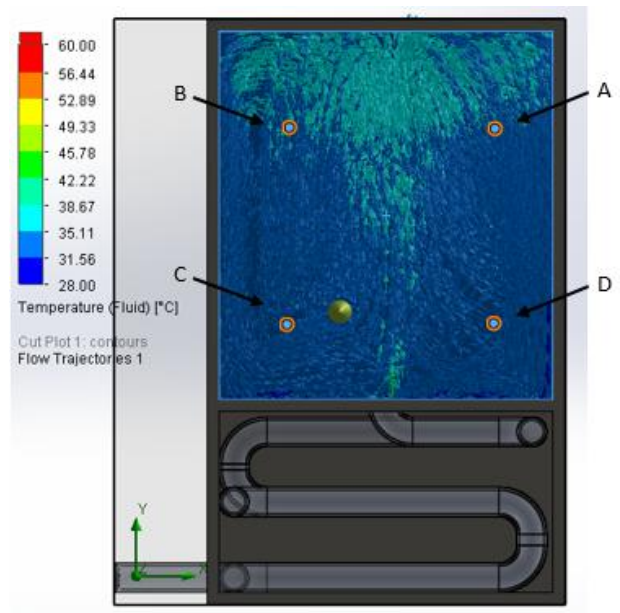

Gambar 7. Hasil Simulasi Tipe Air-Tube

Dari hasil simulasi didapatkan data temperatur pada keempat titik yang ditunjukkan dalam Tabel 2.

Tabel 2. Hasil simulasi tipe air-tube

\begin{tabular}{|l|c|r|r|r|}
\hline \multicolumn{2}{|l|}{ Point Parameters } & & \\
\hline \multicolumn{3}{|c|}{ Global Coordinate System } & & \\
\cline { 1 - 4 } Medium - Fluid; Time $=300 \mathrm{~s}$ & & $\begin{array}{l}\text { Temperature } \\
\text { (Fluid) }\left[{ }^{\circ} \mathrm{C}\right]\end{array}$ \\
\hline Point & $\mathrm{X}$ [m] & $\mathrm{Y}[\mathrm{m}]$ & $\mathrm{Z}[\mathrm{m}]$ & 35,2323966 \\
\hline A & 0,60180 & 0,76494 & 0,78081 & 35,23384634 \\
\hline B & 0,25665 & 0,76698 & 0,78081 & 33,38750243 \\
\hline C & 0,25256 & 0,42999 & 0,78081 & 33,40859327 \\
\hline D & 0,59976 & 0,43203 & 0,78081 & 33 \\
\hline
\end{tabular}


3. Tipe fire-tube dengan bevel

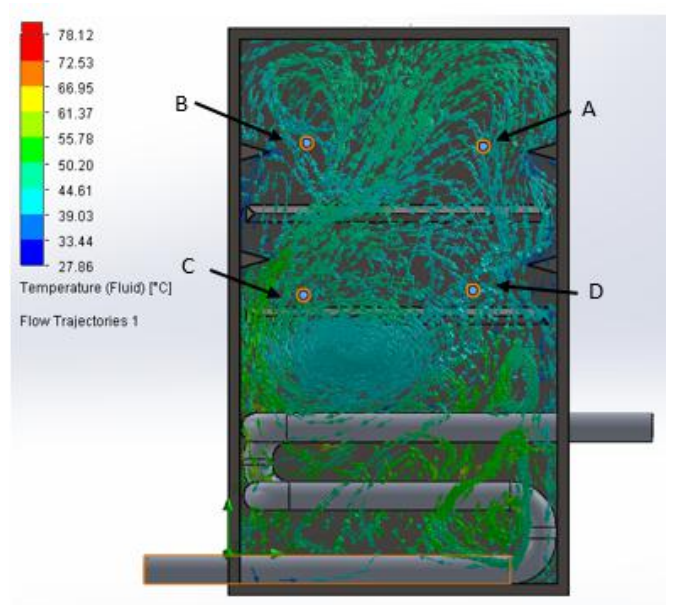

Gambar 8. Hasil Simulasi Tipe Fire-Tube Dengan Bevel

Dari hasil simulasi didapatkan data temperatur pada keempat titik yang ditunjukkan dalam tabel berikut :

Tabel 3. Hasil simulasi tipe fire-tube dengan bevel

\begin{tabular}{|c|r|r|r|r|}
\hline \multicolumn{2}{|l|}{ Point Parameters } & & \\
\hline \multicolumn{2}{|l|}{ Global Coordinate System } & & \\
\cline { 1 - 4 } \multicolumn{2}{|l|}{ Medium - Fluid; Time $=300 \mathrm{~s}$} & & \multirow{2}{*}{$\begin{array}{l}\text { Temperature } \\
\text { (Fluid) }\left[{ }^{\circ} \mathrm{C}\right]\end{array}$} \\
\hline point & $\mathrm{X}[\mathrm{m}]$ & $\mathrm{Y}[\mathrm{m}]$ & $\mathrm{Z}[\mathrm{m}]$ & 43,43 \\
\hline A & 0,5409 & 0,70464 & 0,83953 & 45,05 \\
\hline B & 0,24639 & 0,71078 & 0,83953 & 45,89 \\
\hline C & 0,24025 & 0,40392 & 0,83953 & 43,26 \\
\hline D & 0,54710 & 0,40597 & 0,83953 & \\
\hline
\end{tabular}

\section{Perbandingan Hasil Simulasi}

Dari hasil simulasi ketiga desain sistem distribusi panas ruang pengering didapatkan data perbandingan sebagai berikut:

Tabel 4. Perbandingan temperatur hasil simulasi

\begin{tabular}{|c|c|c|c|}
\hline Point & \multicolumn{3}{|c|}{ Temperatur $\left({ }^{\circ} \mathrm{C}\right)$} \\
\hline & fire-tube & air-tube & fire-tube dengan bevel \\
\hline A & 46,345613 & 35,232397 & 43,43 \\
\hline B & 47,691498 & 35,233846 & 45,05 \\
\hline C & 47,127338 & 33,387502 & 45,89 \\
\hline D & 45,819899 & 33,408593 & 43,26 \\
\hline
\end{tabular}


Dari Tabel 4 dapat dibuat grafik seperti pada Gambar 9.

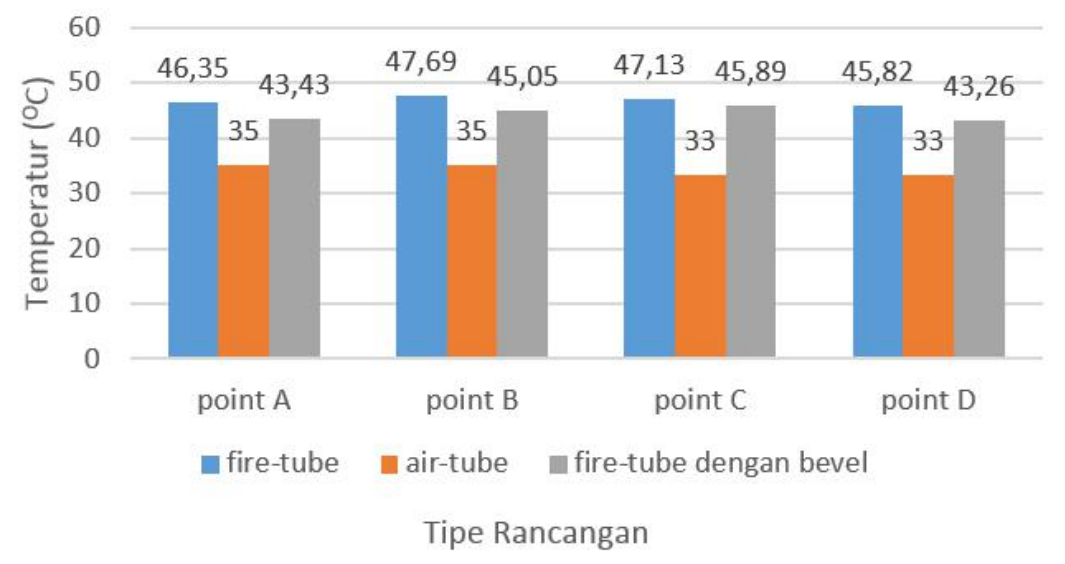

Gambar 9. Grafik Perbandingan Temperatur Hasil Simulasi

\section{PEMBAHASAN}

Pada desain mesin pengering tipe fire-tube, gas hasil pembakaran dialirkan melalui tube untuk memanaskan udara yang ada di ruang bakar. Udara panas hasil pembakaran ini akan memanaskan tube hingga suhu $80^{\circ} \mathrm{C}$. Temperatur tube dijaga konstan $80^{\circ} \mathrm{C}$ dengan mengatur elemen pemanas listrik agar udara di ruang bakar tidak terlalu panas. Kemudian panas dari tube akan dikonveksikan ke udara yang ada di ruang bakar. Pada desain tipe fire-tube ini, terjadi konveksi alami di ruang bakar karena tidak ada pengaruh dari luar sehingga udara yang ada di ruang bakar akan bersirkulasi akibat adanya bouyancy force.

Pada desain mesin pengering tipe air-tube, mesin pengering dibagi menjadi dua ruang yang dipisahkan oleh sekat, ruang di bagian bawah adalah ruang bakar dan di bagian atas adalah ruang pengering. Di ruang bakar, tube dipanaskan hingga mencapai suhu $80^{\circ} \mathrm{C}$ kemudian udara dialirkan dengan kecepatan $4.5 \mathrm{~m} / \mathrm{min}$ melalui tube. Udara akan menerima panas dari tube dan kemudian akan mengalir ke ruang pengering.

Pada desain mesin pengering tipe fire-tube dengan bevel, gas hasil pembakaran dialirkan melalui tube untuk memanaskan udara yang ada di ruang bakar. Perbedaan antara tipe ini dan tipe fire-tube adalah pada tipe ini terdapat bevel untuk membuat aliran semakin turbulent.

Gambar 9. menunjukkan grafik perbandingan temperatur hasil simulasi di empat titik parameter. Berdasarkan grafik tersebut diketahui bahwa tipe fire-tube memiliki sistem distribusi panas yang paling baik dengan rata - rata temperatur di dalam ruang pengering $46.74{ }^{\circ} \mathrm{C}$. Hal ni tidak jauh berbeda dengan tipe fire-tube dengan bevel yang menunjukkan hasil temperatur rata - rata $44.40^{\circ} \mathrm{C}$. Sedangkan tipe air-tube menunjukkan hasil temperatur rata - rata $34.31^{\circ} \mathrm{C}$.

Kurangnya temperatur yang didapat pada hasil simulasi desain tipe air-tube terjadi karena adanya head-losses pada aliran udara saat melewati tube. Sedangkan pada desain tipe fire-tube udara bergerak secara bebas tanpa adanya head-losses sehingga suhu yang diterima pada keempat titik parameter lebih optimal.

Faktor lain yang juga mempengaruhi temperatur di ruang bakar pada ketiga desain tersebut adalah permukaan kontaknya terhadap tube. Dimana pada desain tipe air-tube, udara hanya menerima panas dari permukaan kontak saat mengalir 
melewati tube. Sedangkan pada desain tipe fire-tube udara dapat secara bebas bersirkulasi dan menerima panas dari permukaan kontak.

\section{KESIMPULAN}

Berdasarkan hasil simulasi menggunakan software Solidworks di empat titik parameter terhadap ketiga desain mesin pengering ikan dengan variasi yaitu tipe fire-tube, tipe fire-tube dengan bevel, dan tipe air-tube maka didapatkan desain yang terbaik adalah tipe fire-tube yang dapat mendistribusikan panas rata - rata $46.74{ }^{\circ} \mathrm{C}$. Desain dengan tipe ini memiliiki sistem distribusi panas dengan aliran udara yang bebas sehingga mempercepat proses pendistribusian panasnya.

\section{DAFTAR PUSTAKA}

Apriliyadi, dkk. 2014. Perancangan Mesin Pengering Ikan Dengan Menggunakan Sistem Kendali Logika Fuzzy. Jurnal penelitian. Padang : Fakultas teknologi Industri, Universitas Bung Hatta.

Holman.J.P. 1997. Perpindahan Kalor. Diterjemahkan oleh : E. Jasjfi. Jakarta : Erlangga.

Wilbert F. Stoecker, dan Jerold W. Jones. 1982. Refrigeration and air conditioning. New york : McGraw-Hill.

William C. Reynolds, dan Henry C. Perkins. 1968. Engineering Thermodynamics. New york: McGraw-Hill. 